\title{
BEBIDA LÁCTEA COM LEITE CAPRINO E SORO CAPRINO É ALTERNATIVA PARA APROVEITAMENTO DA POLPA DE UMBU
}

\section{Milk drink with goat milk and goat serum is alternative for exploitation of pulp umbu}

Nkarthe Guerra Araújo ${ }^{{ }^{*}}$, Fabrizio Fonseca Barbosa ${ }^{2}$

\section{RESUMO}

Esta pesquisa teve por objetivo desenvolver e avaliar a aceitação e intenção de compra de duas formulações de bebidas lácteas fermentadas elaboradas com umbus, soro caprino e leite caprino, visando agregar maior valor econômico às três matérias-primas. Os tratamentos constaram da variação nas concentrações de soro caprino $(28,5 \%$ e $44 \%)$ e leite caprino $(44 \%$ e $28,5 \%)$ respectivamente. A polpa foi previamente analisada e apresentou $15,21 \mathrm{mg} / 100 \mathrm{~g}$ de ácido ascórbico. As bebidas lácteas fermentadas apresentaram características microbiológicas dentro do estabelecido pela legislação. Verificou-se que não houve diferença significativa $(\mathrm{p}>0,05)$ para os atributos cor, aroma e consistência de ambas, entretanto, os atributos sabor e aceitação global foram significativamente afetados. A formulação com $28,5 \%$ de soro caprino e $44 \%$ de leite caprino apresentou as melhores médias a partir de 10 dias, sendo aceita até 25 dias de armazenamento.

Palavras-chave: aceitação sensorial; ácido ascórbico; soro de queijo.

\begin{abstract}
This research aimed to develop and evaluate the acceptance and intention to purchase two dairy beverages formulations prepared with fermented umbus, goat serum and goat milk in order to add greater economic value to the three raw materials. The treatments consisted of the variation in serum concentrations goat $(28,5 \%$ and $44 \%)$ and goat milk (44\% and $28,5 \%)$, respectively. The pulp

1 Universidade Federal da Paraíba (UFPB), Cidade Universitária, 58051-900, João Pessoa, PB, Brasil. E-mail: nkarthe@gmail.com

2 Universidade Federal de Pelotas (UFPEL), Campus Capão do Leão, Capão do Leão, RS, Brasil.

* Autor para correspondência.
\end{abstract}


has previously been analyzed and showed $15,21 \mathrm{mg} / 100 \mathrm{~g}$ of ascorbic acid. The fermented dairy beverages showed microbiological characteristics within the established by the legislation. It was found that there was no significant difference $(p>0,05)$ for color attributes, flavor and consistency of both, however, the flavor attributes and global acceptance have been significantly affected. The formulation with $28,5 \%$ of goat serum and $44 \%$ goat milk had the best average from 10 days, and acceptances up to 25 days of storage.

Keywords: sensory acceptance; ascorbic acid; cheese whey.

\section{INTRODUÇÃO}

Nativo da região semi-árida do Nordeste brasileiro, o umbuzeiro (Spondias tuberosa Arruda) apresenta excelente capacidade produtiva, e seus frutos, características nutricionais relevantes, especialmente como fonte de ácido ascórbico, além de substâncias biologicamente ativas, como clorofila, carotenoides e flavonoides (OLIVEIRA et al., 2013). Entretanto, devido à falta de conhecimento da população sobre o valor nutritivo, elevada perecibilidade e especialmente os baixos preços com que são comercializados os frutos in natura, estes não são devidamente aproveitados. Segundo Paula et al. (2012), em média, um produtor rural comercializa $45 \mathrm{~kg}$ de umbu por $\mathrm{R} \$ 17,00$, enquanto $60 \mathrm{~kg}$ do mesmo, após a elaboração de derivados como doces, suco ou geleia pode elevar o rendimento para $\mathrm{R} \$ 135,00$. O desenvolvimento de uma bebida láctea com leite caprino destaca-se, pois além do aproveitamento do leite para consumidores com necessidades especiais, agregaria maior valor econômico ao fruto, além de contribuir com a redução do descarte inadequado do soro de queijos no meio ambiente.

Quando comparado ao leite bovino, o caprino é comprovadamente um alimento de melhor disponibilidade de nutrientes e também diferem na composição de aminoácidos. Em média, cerca de $40 \%$ de pacientes sensíveis as proteínas do leite de vaca toleram a proteína do leite de cabra. O conteúdo mineral, especialmente de ferro é superior, podendo ajudar na prevenção da anemia ferropriva.
Além disso, apresenta maior digestibilidade, podendo ser indicado como substituto do leite bovino na alimentação de crianças desnutridas e no tratamento de diabéticos (ANAETO et al., 2010). Apesar disso, a aceitação do leite caprino ainda traz receio, devido ao odor característico que o mesmo apresenta (CORREIA et al., 2008), podendo ser melhorado pela adição de polpa de frutas aos produtos que o contém em sua formulação.

O soro também apresenta elevado valor nutricional, uma vez que retém cerca de 55\% dos nutrientes do leite (LEITE et al., 2012). É composto por água, lactose, proteínas, gorduras e sais minerais, especialmente o cálcio (PESCUMA et al., 2010), além de ácido láctico, ácido cítrico, compostos nitrogenados não proteicos e vitaminas do complexo B (DRAGONE et al., 2009). Por apresentar estes nutrientes, uma das alternativas de aproveitamento do mesmo é na formulação de bebidas lácteas, contudo, segundo Magalhães et al. (2011) no Brasil, cerca de 50\% do soro decorrente da produção de queijos ainda não é aproveitado devido ao grande volume produzido, ocasionando desperdício nutricional, perda financeira e impactos ambientais relevantes.

Neste contexto, este trabalho teve por objetivo, desenvolver e avaliar a aceitação e intenção de compra de uma nova opção de sabor de bebida láctea fermentada, elaborada com três matérias-primas de considerável valor nutricional, mas, altamente perecíveis, de baixo valor econômico agregado e abundantes na região de Campina Grande-PB. 


\section{MATERIAL E MÉTODOS}

Os umbus maduros, bem como, o soro caprino e o leite caprino foram adquiridos no município de Barra de Santana, localizado na região metropolitana de Campina GrandePB. Para obtenção da polpa, os frutos foram sanitizados em água clorada a $5 \mathrm{ppm}$, branqueados a $90{ }^{\circ} \mathrm{C}$ por $5 \mathrm{~min}$, triturados em multiprocessador e em seguida, transferidos para uma peneira de náilon, onde foram removidos os caroços e resíduos da casca. Foram elaboradas duas formulações de bebidas lácteas fermentadas utilizando-se soro caprino e leite caprino, sacarose (11\%), amido $(1,48 \%)$, cultura mista de Streptococcus thermophilus e Lactobacillus bulgaricus $(0,02 \%)$ e polpa de umbu $(15 \%)$. Os tratamentos constaram da variação nas concentrações de soro caprino e leite caprino de $(28,5 \%$ e $44 \%)$ e $(44 \%$ e $28,5 \%)$, respectivamente. Após pasteurização $\left(95^{\circ} \mathrm{C} / 5 \mathrm{~min}\right)$, resfriamento $\left(42^{\circ} \mathrm{C}\right)$, fermentação $\left(42^{\circ} \mathrm{C} / 4 \mathrm{~h}\right)$ seguido de resfriamento $\left(4 \pm 1{ }^{\circ} \mathrm{C}\right)$, foi adicionada às bebidas lácteas fermentadas $15 \%$ de polpa de umbu $(89,80 \%$ de umidade, $15,21 \mathrm{mg} / 100 \mathrm{~g}$ de ácido ascórbico, 1,72\% de acidez titulável, pH 2,13 e 1,29\% de cinzas) e em seguida, estas foram acondicionadas em garrafas de poliestireno, armazenadas a $5 \pm 1{ }^{\circ} \mathrm{C}$ e submetidas imediatamente as análises microbiológicas. As análises sensoriais foram realizadas em diferentes intervalos 0 , 10, 15, 20, 25, 28 dias.

A formulação da bebida que apresentou maior aceitação e intenção de compra por parte dos consumidores foi submetida às análises físico-químicas aos 25 dias de armazenamento.

\section{Análises microbiológicas}

As duas formulações desenvolvidas foram submetidas à pesquisa do número mais provável de coliformes totais e a $45^{\circ} \mathrm{C}$,
Staphylococcus coagulase positiva, Salmonella sp e bactérias lácticas (APHA, 2001).

\section{Análises sensoriais}

As análises sensoriais de aceitação e intenção de compra foram realizadas com 60 julgadores não treinados de ambos os gêneros, com idade variando entre 18 a 29 anos. O grau de aceitação foi avaliado por meio de teste afetivo laboratorial com uso de escala hedônica de nove pontos $(9=$ gostei muitíssimo, 1 = desgostei muitíssimo) para os atributos, cor, aroma, consistência, sabor e aceitação global. A intenção de compra foi avaliada por meio de escala hedônica, de cinco pontos $(5=$ certamente compraria; $1=$ certamente não compraria) (MEILGAARD et al., 1991). As análises foram realizadas em uma Escola Estadual, localizada no município de Caturité-PB.

Para ambos os testes sensoriais as bebidas lácteas fermentadas foram servidas em copos descartáveis de $50 \mathrm{~mL}$ codificados com números aleatórios de três dígitos, sendo oferecidos biscoitos (água e sal) e água mineral entre os intervalos de cada análise. Os testes foram realizados e interrompidos quando as amostras apresentaram rejeição (médias $<6,0)$ e estas foram rejeitadas em intervalos distintos. Deste modo, a partir do resultado da análise em determinado intervalo foi estabelecido o tempo que a próxima seria analisada. Assim, os testes das bebidas lácteas fermentadas com variação na concentração de soro caprino e leite caprino de $(28,5 \%$ e $44 \%)$ e $(44 \%$ e $28,5 \%)$ foram realizados nos intervalos $0,10,15,20,25,28$ dias e 0,10 , 15 e 20 dias respectivamente.

\section{Análises físico-químicas}

As análises físico-químicas foram realizadas para a amostra que apresentou melhores resultados quanto à aceitação e intenção de compra do produto, aos 25 dias de arma- 
zenamento. Foram realizadas análises de $\mathrm{pH}$, acidez total titulável, lipídios, proteínas, cinzas, umidade, atividade de água e ácido ascórbico, seguindo-se a metodologia proposta pela Association Official Analytical Chemists (AOAC, 2000). A polpa foi caracterizada no primeiro dia de armazenamento (ácido ascórbico, acidez total titulável, cinzas, $\mathrm{pH}$, atividade de água e umidade) segundo a mesma metodologia.

\section{Análise estatística dos dados}

Foi utilizado o delineamento inteiramente casualizado (DIC). Os resultados das análises sensoriais foram submetidos à análise de variância (ANOVA) e comparação de médias pelo Teste de Tukey ao nível de 5\% de significância, utilizando-se o Programa Assistat 7.7. Foi avaliado se houve diferença significativa $(\mathrm{p}<0,05)$ apenas entre os períodos de armazenamento de cada formulação: A $(28,5 \%$ de soro caprino e $44 \%$ de leite caprino) aos $(0,10,15,20,25,28$ dias) e B (44\% de soro caprino e $28,5 \%$ de leite caprino) nos intervalos $(0,10,15$ e 20 dias). Entretanto, os resultados da formulação (A), aceita até 25 dias não foi comparada estatisticamente aos da formulação (B), que obteve aceitação apenas até os 15 dias, uma vez que, ao se interromper as análises quando as amostras foram rejeitadas, obtiveram-se intervalos distintos entre as formulações.

\section{RESULTADOS E DISCUSSÃO}

As duas formulações desenvolvidas apresentaram ausência de coliformes totais e a $45^{\circ} \mathrm{C}$ e de Salmonella sp., estando dentro do padrão estabelecido pela legislação (ANVISA, 2001), além da ausência de Staphylococcus coagulase positiva, o que indica boas práticas higiênicas durante o processamento. A contagem média de bactérias lácticas da formulação A foi $1,3 \times 10^{7} \mathrm{UFC} / \mathrm{g}$ e B $1,1 \times 10^{6} \mathrm{UFC} / \mathrm{g}$, respectivamente, sendo recomendado pela legislação em vigor (BRASIL, 2005), valor mínimo de $10^{6} \mathrm{UFC} / \mathrm{g}$.

No teste de aceitação, as duas formulações desenvolvidas apresentaram boas médias para os atributos cor: A $(8,0$ a 8,2$)$ e B $(8,3$ a 8,1$)$, aroma: A $(8,1$ a 7,9$)$ e B $(8,2$ a 8,0$)$ e consistência: A $(8,4$ a 8,2$)$ e B $(8,0$ a 7,9$)$, não sendo significativamente afetados $(p>0,05)$ em função do período de armazenamento (Figura 1A, 1B). Contudo o atributo sabor das duas formulações foi significativamente afetado ao longo do tempo, contribuindo com a rejeição sensorial do produto, sendo a formulação com $44 \%$ de soro caprino e $28,5 \%$ de leite caprino a que obteve menores médias, variando de 7,5 a 4,6.

A aceitação global de ambas as formulações diminuiu com o aumento do período de armazenamento $(\mathrm{p}<0,05)$ (Figura 2A, 2B). As bebidas lácteas fermentadas foram consideradas rejeitadas quando apresentaram médias < 6,0 (GIMÉNEZ et al., 2007). Deste modo, as formulações com variação nas concentrações de soro caprino e leite caprino de $(28,5 \%$ e $44 \%)$ e $(44 \%$ e $28,5 \%)$ foram aceitas até 25 e 15 dias, quando apresentaram escores médios 6,7 e 6,5, respectivamente.

Santos et al. (2006), analisaram quatro diferentes formulações de bebida láctea de umbu com leite de vaca e obtiveram escores médios variando de 5,29 a 6,93. Isto sugere que as formulações desenvolvidas com soro caprino e leite caprino nesta pesquisa foram mais bem aceitas que a desenvolvida por Santos et al. (2006).

Para verificar a intenção de compra, Guerra et al. (2011) relataram médias entre 3,5 a 3,8 como satisfatórias. Nesta pesquisa, até os 25 dias, as médias da formulação A (28,5\% de soro caprino e $44 \%$ de leite caprino) variou de 4,6 a 3,8, sendo significativamente afetadas $(\mathrm{p}<0,05)$ pelo aumento do período de armazenamento. A intenção de compra ratifica a boa aceitação encontrada. Já a formulação B, desenvolvida com $44 \%$ de soro caprino $28,5 \%$ de leite caprino até os 15 dias em 
que foi aceita, apresentou médias inferiores, variando de 3,0 a 2,0, correspondendo ao termo hedônico "Talvez comprasse talvez não comprasse" e "Provavelmente não compraria".

A análise físico-química da formulação A $(28,5 \%$ de soro caprino e $44 \%$ de leite caprino) está na Tabela 1 . As médias são de três repetições, analisadas aos 25 dias de armazenamento da bebida láctea fermentada.

Os resultados são superiores ao rela- tado por Santos et al. (2006), que obtiveram valores de 3,67 para o $\mathrm{pH}, 0,78 \%$ de lipídeos e $0,37 \%$ de cinzas em bebida láctea elaborada com polpa de umbu e leite de vaca. O baixo teor de gordura está dentro do estabelecido pela legislação, que indica o mínimo de 2,0\% (BRASIL, 2005) e constitui mais uma opção a consumidores preocupados com o elevado consumo calórico e que necessitam de uma dieta especial na alimentação. Já
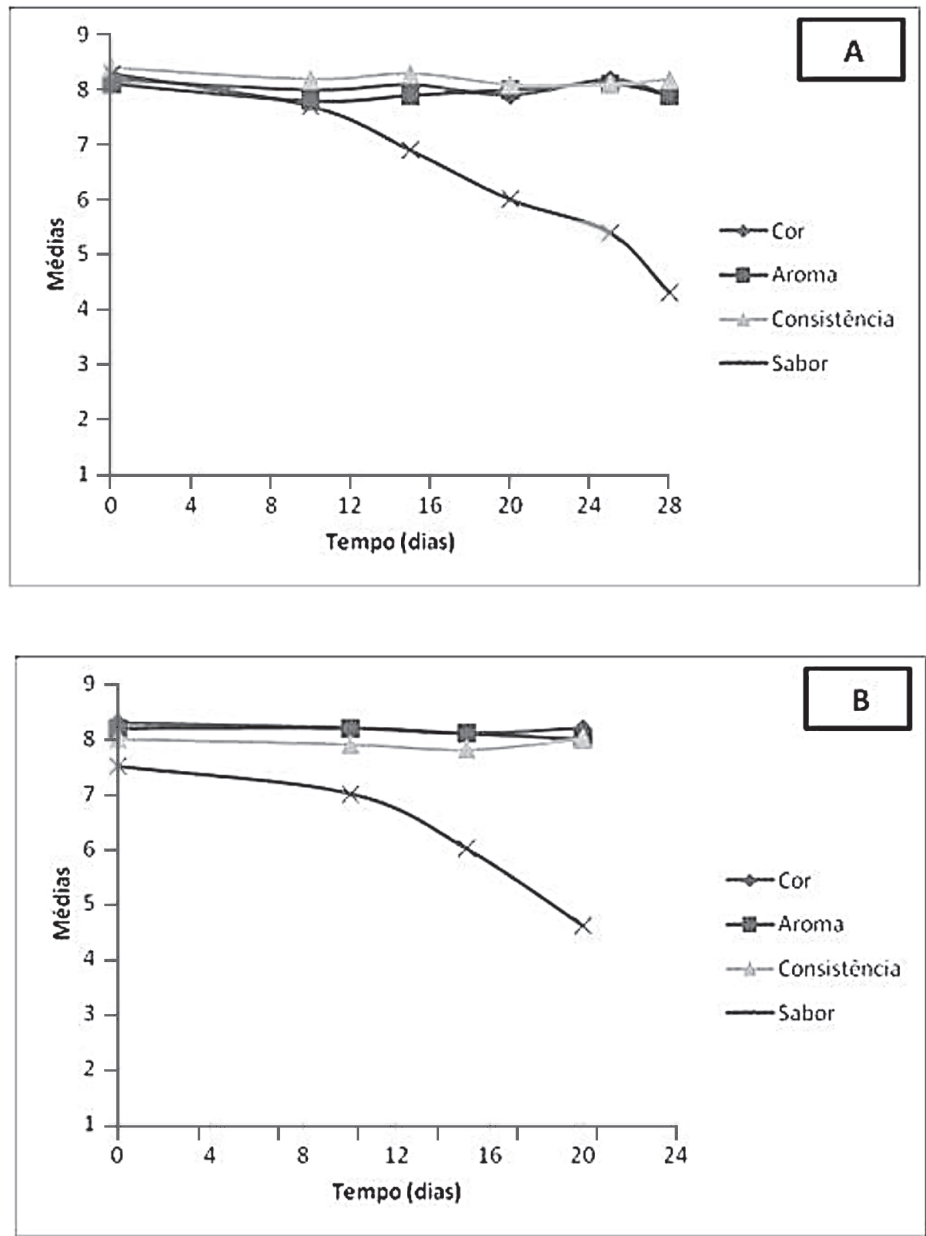

Figura 1 - Médias obtidas para os atributos cor, aroma, consistência e sabor de bebida láctea fermentada sabor umbu, elaborada com $28,5 \%$ de soro caprino e $44 \%$ de leite caprino (1A) e $44 \%$ de soro caprino e $28,5 \%$ de leite caprino (1B) por 60 provadores não treinados 
o baixo valor de $\mathrm{pH}$ contribui com a inibição do desenvolvimento da maioria dos microrganismos durante o período de armazenamento da bebida láctea.

Marinho et al. (2012), analisando iogurte com $20 \%$ de polpa de umbu e leite caprino obtiveram menor teor de proteínas, 2,31\%, o que indica maior valor proteico a bebida láctea que ao iogurte. Quanto a análise de ácido ascórbico, esta apresentou elevado teor
$(13,97 \mathrm{mg} / 100 \mathrm{~g})$, o que pode está relacionado a embalagem na qual foi armazenada e ao processamento, uma vez que a polpa só foi adicionada após pasteurização e resfriamento da bebida láctea fermentada. A deficiência de ácido ascórbico no organismo pode ocasionar diversas doenças, sendo a ingestão desta vitamina essencial, uma vez que nosso organismo é incapaz de sintetizá-la (IQBAL et al., 2004).
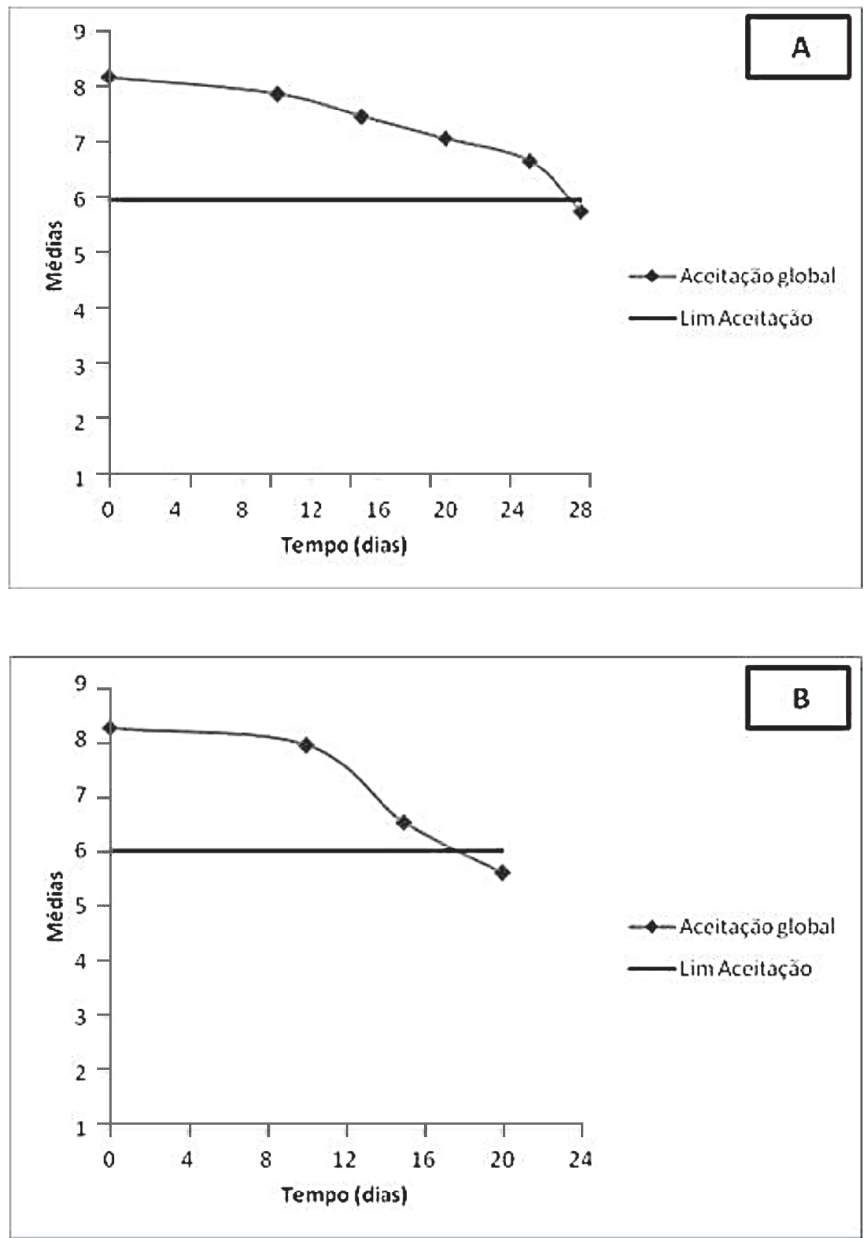

Figura 2 - Médias da aceitação global de bebida láctea fermentada sabor umbu, elaborada com $28,5 \%$ de soro caprino e $44 \%$ de leite caprino (2A) e $44 \%$ de soro caprino e $28,5 \%$ de leite caprino (2B) por 60 provadores não treinados 
Tabela 1 - Análises físico-químicas da bebida láctea fermentada sabor umbu produzida com $28,5 \%$ de soro caprino e $44 \%$ de leite caprino após 25 dias de fabricação e armazenada a $5 \pm 1{ }^{\circ} \mathrm{C}$

\begin{tabular}{cc}
\hline Análise $^{1}$ & Bebida láctea \\
\hline Umidade (\%) & 86,30 \\
Cinzas (\%) & 1,51 \\
Atividade de Água & 0,910 \\
pH & 3,69 \\
Acidez titulável & 0,82 \\
(\% ácido láctico) & 2,51 \\
Lipídeos (\%) & 9,34 \\
Proteínas (\%) & 13,97 \\
\hline Ácido ascórbico (mg/100g)
\end{tabular}

${ }^{1}$ Média de três repetições

\section{CONCLUSÕES}

O desenvolvimento da bebida láctea fermentada sabor umbu, com variação na concentração de $28,5 \%$ de soro caprino e $44 \%$ de leite caprino permite a obtenção de um produto com boa aceitação sensorial e intenção de compra durante 25 dias de armazenamento. Ao mesmo tempo, possibilita a obtenção de um produto de simples execução, elevado valor nutricional e baixo custo, mostrando-se como alternativa promissora de forma a agregar maior valor econômico aos frutos do umbuzeiro, bem como ao soro caprino e leite caprino. Essa bebida láctea permite reduzir o desperdício de soro, aumentar a renda dos produtores rurais, dos pequenos laticínios e diversificar a oferta de uma nova opção de sabor de bebida láctea fermentada no estado da Paraíba-PB.

\section{REFERÊNCIAS}

AGÊNCIA NACIONAL DE VIGILÂNCIA SANITÁRIA (ANVISA). Resolução RDC $\mathrm{n}^{\circ} 12$, de 02 de janeiro de 2001. Aprova o Regulamento Técnico sobre Padrões Microbiológicos para Alimentos. Diário Oficial da República Federativa do Brasil, Brasília, 10 jan. 2001. Seção 1, p. 45-53.

AMERICAN PUBLIC HEALTH ASSOCIATION (APHA). Compendium of methods for the microbiological examination of foods. 4.ed. Washington: APHA, 2001.676 p.

ANAETO, M. et al. Goat products: Meeting the challenges of human health and nutrition. Agriculture and Biology Journal of North America, v. 1, n. 6, p. 1231-1236, 2010.

ASSOCIATION OFFICIAL ANALYTICAL CHEMISTS (AOAC). Official Methods of Analysis OF AOAC International. 17 ed. Gaithersburg, MD: Association of Official Analytical Chemistry International, 2000. $2200 \mathrm{p}$.

BRASIL. Ministério da Agricultura, Pecuária e Abastecimento. Instrução Normativa $\mathrm{n}^{\mathrm{o}} 16$, de 23 de agosto de 2005. Aprova o Regulamento técnico de identidade e qualidade de bebida láctea. Diário Oficial da República Federativa do Brasil, Brasília, 24 ago. 2005. Seção 1, p. 7.

CORREIA, R. T. P. et al. Sorvetes elaborados com leite caprino e bovino: Composição química e propriedades de derretimento. Revista Ciências Agronômicas, v. 39, n. 2, p. 251-256, 2008.

DRAGONE, G. et al. Characterization of volatile compounds in an alcoholic beverage produced by whey fermentation. Food Chemistry, v. 112, n. 4, p. 929-935, 2009.

GIMÉNEZ, A. et al. Shelf life estimation of Brown pan Bread: A consumer approach: Journal Food Quality and Preference, v. 18, n. 2, p. 196-204, 2007. 
GUERRA, I. C. D. et al. Evaluation of goat mortadella prepared with different levels of fat and goat meat from discarded, Animals Small Ruminant Research, v. 98, n. 1-3, p. 59-63, 2011.

IQBAL, K. et al. Biological significance of ascorbic acid (vitamina $\mathrm{C}$ ) in human healthA review. Journal of Nutrition, v. 3, n. 1, p. 5-13, 2004.

LEITE, M. T. et al. Canonical analysis technique as an approach to determine optimal conditions for lactic acid production by Lactobacillus helveticus. International Journal of Chemical Engineering, v. 2012, Article ID 303874, 9 p., 2012. doi: $10.1155 / 2012 / 303874$.

MAGAlHÃES, K. T. et al. Comparative study of the biochemical changes and volatile compound formations during the production of novel whey-based kefir beverages and traditional milk kefir. Food Chemistry, v. 126, n. 1, p. 249-253, 2011.

MARINHO, M. V. M. et al. Análise físicoquímica e sensorial de iogurte de leite de cabra com polpa de umbu. Revista Brasileira de Produtos Agroindustriais, v. 14, n. especial, p. 497-510, 2012.

MEILGAARD, M. et al. Sensory Evaluation Techniques. London: CRP Press, 1991.p. 287.

OLIVEIRA, C. F. P. et al. Estudio del proceso de deshidratación osmótica de umbu (Spondias tuberosa Arruda Câmara). Semina: Ciências Agrárias, v. 34, n. 2, p. 729-740, 2013.

PAULA, B. et al. Produção e caracterização físico-química de fermentado de umbu. Ciência Rural, v. 42, n. 9, p. 1688-1693, 2012.

PESCUMA, M. et al. Functional fermented whey-based beverage using lactic acid bacteria. International Journal of Food Microbiology, v. 141, n. 1-2, p. 73-81, 2010.

SANTOS, C. T. et al. Elaboração e caracterização de uma bebida láctea fermentada com polpa de umbu. Revista Brasileira de Produtos Agroindustriais, v. 8, n. 2, p. 111-116, 2006. 